\section{Correspondence on 'Risk of venous thromboembolism in knee, hip and hand osteoarthritis: a general population-based cohort study'}

We found the article by Zeng et al extremely interesting. ${ }^{1}$ They reported that knee or hip osteoarthritis (OA), but not hand OA, was associated with an increased risk of venous thromboembolism (VTE). This population-based cohort study used datasets from the Health Improvement Network, from January 2000 to December 2017, to compare the incidence of VTE between joint and non-joint replacements in OA patients and non-OA controls using matching methods by age, sex, entry time and body mass index. The author concluded that OA was associated with an increased risk for VTE in knee or hip OA patients, which was partially mediated through knee or hip replacement. Although the findings of this study may be significant for clinicians, some issues remain unaddressed in this regard. Thus, we would like to raise the following points.

First, we know that immobilisation is crucial for VTE to occur, and the risk of VTE will increase with prolonged immobility, especially in elderly individuals with an active platelet reactivity and higher plasma levels of coagulation factors than in young people. ${ }^{2}$ The immobilisation duration is a strong independent predictor of postoperative VTE. ${ }^{3}$ Recent reports have emphasised the importance of early mobilisation in the prevention of VTE for patients undergoing hip or knee replacement. ${ }^{56}$ However, the duration of immobilisation was not described in the baseline characteristics of these two groups. Therefore, the conclusions may not be rigorous without considering these vital factors.

Second, VTE rates are high for both surgical and non-surgical hospitalised patients without prophylaxis. The incidence of VTE varies in both surgical and non-surgical patients who are admitted in US hospitals for specific procedures each year: venous thrombotic events may occur in up to $20 \%$ of surgical patients and $16 \%$ of non-surgical patients without prophylaxis. ${ }^{78}$ For example, several previous studies in major surgical patients have demonstrated that extended thromboprophylaxis significantly reduces postdischarge VTE when compared with short-term therapy. ${ }^{9-11}$ Furthermore, extended thromboprophylaxis therapy has been established to be associated with a lower risk for postdischarge VTE in patients with non-major surgery. ${ }^{12}$ However, the percentages of both surgical and non-surgical hospitalised patients without prophylaxis were not described in the baseline characteristics of these two groups, which might have nullified some of the study-related results.

Finally, the Caprini Risk Score (CRS) is a validated tool created to stratify the VTE risk in medical inpatients effectively and identify surgical patients with a high risk of VTE occurrence. ${ }^{13} 14$ The use of risk assessment tools has also been well demonstrated to empower physicians to improve the VTE prevention with measured mortality benefit. This article conducted three matched cohort studies to compare the risk of VTE among patients with incident knee, hip or hand OA alone, matched by same age, sex, index date and body mass index. As for clinicians, we are more concerned about forming comparable groups with a priori risk for VTE and magnifying hidden confounding variables. We suggest that non-OA patients should be CRS matched to draw accurate or reliable conclusions.

\author{
Tsung-Kun Lin, ${ }^{1,2}$ Lung-Fa Pan, ${ }^{3,4}$ Gwo-Ping Jong ${ }^{5,6}$ \\ 'Department of Pharmacy, Taoyuan Armed Forces General Hospital, Lungtan, \\ Taoyuan, Taiwan \\ ${ }^{2}$ School of Pharmacy, National Defense Medical Center, Taipei, Taiwan \\ ${ }^{3}$ Graduate Institute of Radiological Science, Central Taiwan University of Sciences and \\ Technology, Taichung, Taiwan \\ ${ }^{4}$ Department of Cardiology, Taichung Armed Forces General Hospital, Taichung, \\ Taiwan \\ ${ }^{5}$ Department of Internal Medicine, Chung Shan Medical University Hospital, Taichung, \\ Taiwan \\ ${ }^{6}$ Chung Shan Medical University, Taichung, Taiwan
}

Correspondence to Dr Gwo-Ping Jong, Department of Internal Medicine, Chung Shan Medical University Hospital, Taichung 40201, Taiwan; cgp8009@yahoo.com.tw
Correction notice This article has been corrected since it published first. The provenance and peer review statement has been included.

Acknowledgements We thank Chung Shan Medical University Hospital for expert technical assistance.

Contributors All authors reviewed the draft and approved the submission of the manuscript.

Funding The authors have not declared a specific grant for this research from any funding agency in the public, commercial or not-for-profit sectors.

Competing interests None declared.

Patient and public involvement Patients and/or the public were not involved in the design, or conduct, or reporting, or dissemination plans of this research.

Patient consent for publication Not required.

Provenance and peer review Not commissioned; internally peer reviewed.

(c) Author(s) (or their employer(s)) 2021. No commercial re-use. See rights and permissions. Published by BMJ.

T-KL and L-FP contributed equally.

$$
\text { Check for updates }
$$

To cite Lin T-K, Pan L-F, Jong G-P. Ann Rheum Dis Epub ahead of print: [please include Day Month Year]. doi:10.1136/annrheumdis-2020-219733

Received 16 December 2020

Accepted 18 December 2020

\section{(5) Linked}

https://doi.org/10.1136/annrheumdis-2020-219747

Ann Rheum Dis 2021:0:1. doi:10.1136/annrheumdis-2020-219733

ORCID iD

Gwo-Ping Jong http://orcid.org/0000-0002-7786-5497

\section{REFERENCES}

1 Zeng C, Bennell K, Yang Z, et al. Risk of venous thromboembolism in knee, hip and hand osteoarthritis: a general population-based cohort study. Ann Rheum Dis 2020;79:1616-24.

2 Douce DR, Holmes CE, Cushman M, et al. Risk factors for cancer-associated venous thromboembolism: the venous thromboembolism prevention in the ambulatory cancer clinic (VTE-PACC) study. J Thromb Haemost 2019;17:2152-9.

3 Xia Z-N, Xiao K, Zhu W, et al. Risk assessment and management of preoperative venous thromboembolism following femoral neck fracture. J Orthop Surg Res 2018;13:291.

4 Angchaisuksiri P. Venous thromboembolism in Asia--an unrecognised and undertreated problem? Thromb Haemost 2011;106:585-90.

5 Januel J-M, Chen G, Ruffieux C, et al. Symptomatic in-hospital deep vein thrombosis and pulmonary embolism following hip and knee arthroplasty among patients receiving recommended prophylaxis: a systematic review. JAMA 2012;307:294-303.

6 Lieberman JR, Pensak MJ. Prevention of venous thromboembolic disease after total hip and knee arthroplasty. J Bone Joint Surg Am 2013;95:1801-11.

7 Census UBot. Statistical Abstract of the United States: 2000. 120th ed. Washington, DC, 2000.

8 Geerts WH, Pineo GF, Heit JA, et al. Prevention of venous thromboembolism: the seventh ACCP conference on antithrombotic and thrombolytic therapy. Chest 2004;126:338S-400.

9 Agnelli G, Buller HR, Cohen A, et al. Apixaban for extended treatment of venous thromboembolism. N Engl J Med 2013;368:699-708.

10 Sobieraj DM, Coleman Cl, Pasupuleti V, et al. Comparative efficacy and safety of anticoagulants and aspirin for extended treatment of venous thromboembolism: a network meta-analysis. Thromb Res 2015;135:888-96.

11 Schulman S, Kearon C, Kakkar AK, et al. Extended use of dabigatran, warfarin, or placebo in venous thromboembolism. N Engl J Med 2013;368:709-18.

12 Gould MK, Garcia DA, Wren SM. Prevention of VTe in nonorthopedic surgical patients: antithrombotic therapy and prevention of thrombosis, 9th ED:American College of chest physicians evidence-based clinical practice guidelines. Chest 2012;141

13 Zhou H, Hu Y, Li X, et al. Assessment of the risk of venous thromboembolism in medical inpatients using the Padua prediction score and Caprini risk assessment model. J Atheroscler Thromb 2018;25:1091-104.

14 Li Q, Ba T, Wang L-F, et al. Stratification of venous thromboembolism risk in burn patients by Caprini score. Burns 2019;45:140-5. 